ment must seem to lie within the scope of the authority's expertise and also offer the prospect of technological application "in the foreseeable future". The authority also looks for interested industrial companies to provide finance or other support.

Desalination has been a principal part of the diversification programme and $£ l \cdot 3$ million is being spent on it in the period of three years from April 1965. The Springfields Laboratory, which manufactures fuel elements, is working on a technique for hydrostatic extrusion, chiefly in the hope of producing a 1,600 ton press which promises to reduce the cost of capital equipment in the manufacture of wire bar. A great deal of work has been undertaken on the development of transducers able to turn mechanical into electrical signals. The Culham Laboratory, together with other establishments of the authority, is developing a satellite for the European Space Research Organization, while the Atomic Weapons Research Establishment is developing a sounding rocket for space research. Other work being undertaken by the establishments includes the development of a biological centrifuge, an attempt to foster the use of computers in industry, the development of sensitive analytical techniques for use in the detection of crime, and a search for ways of making some practical use of the research and development already carried out in the use and manipulation of beryllia. The authority is also cheerful about a scheme to convert radioactive heat directly into electricity by means of thermo-electric generators, and it is planned to develop such a device to produce 1 watt of electricity for running a marine navigation light. There is also a refrigerator working within one-tenth of a degree of $0^{\circ} \mathrm{K}$ which is expected to be of some use in lowtemperature research.

\section{Reducing Cost}

THE total staff of the authority is now 33,500 , which represents a reduction of some 1,400 in the course of the year. Wastage still exceeds the reduced demands on the services of staff, with the result that recruitment continues. Steps are being taken to apply work study methods in the industrial establishments, and also to move the factory at Bracknell, which manufactures cans for fuel elements, to Harwell.

The net cost of all this work (with the exclusion of the military costs and subventions which are normally kept secret) amounted to $£ 29$ million in 1965-66. The intention is to reduce this sum by roughly $£ 1$ million in the year ahead. This sum is the figure obtained by deducting from the total cost of operations ( $£ 86$ million in 1965-66) the receipts from sales of materials and other sources. Research and development on nuclear power stations has actually increased slightly between 1964-65 and 1965-66 from $£ 37.5$ million to $£ 39.5$ million. The number of qualified scientists and engineers engaged on this work remains substantially unchanged at roughly 2,650 .

\section{One Town to Share}

The U.S. Atomic Energy Commission seems to have been over-optimistic in tackling the invidious problem of deciding where in the United States to put the new $200 \mathrm{GeV}$ accelerator. For more than a year the AEC has been investigating eight sites all over the United States. A team of experts from the National Academy of Sciences has been going through a similar but parallel study. The AEC seems to have been conscious from the start of the difficulty of the choice that would have eventually to be made. One sharp official from the White House staff particularly admired the way in which the teams of visiting experts would take care to see that local politicians were in attendance and ready to make the inevitable speech about being willing to subordinate local interests to the greater good of science. With luck, according to this calculation, all the politicians with a vested interest in the siting of the reactor would be on record as supporters of pure reason and not parochialism. In this spirit the AEC published the names of half a dozen possible sites, one of which was effectively eliminated when the residents of a Chicago suburb said they did not want the accelerator built in their neighbourhood. In the past few months it has been supposed that a final decision would be made after the congressional elections in November.

This cheerful expectation has now been complicated by the threat of protest on behalf of one city, whose proposed accelerator site was not included in the short list. Senator Warren G. Magnusson of Washington is preparing to take up cudgels on behalf of St. Louis. Unlike the Atomic Energy Commission, St. Louis will gain nothing by waiting until after the election, although there is always the possibility that the Congress which finished off the Mohole without com. punction will not shrink from cancelling (or postponing) the accelerator as well.

\section{Hovercraft against Poachers}

THE extra speed of the hovercraft was put to a practical test by the Royal Navy this week off Skegness; the Interservice Hovercraft Trials Unit provided an SRN-5 to investigate the ship's usefulness for poacher interception and arrest, coastal fishery protection patrols and mobile support facilities for fishery protection duties.

\section{Basic Research}

THE Warren Spring Laboratory of the Ministry of Technology is to become a national centre for the exchange, correlation, translation and formulation of computer programmes for use in chemical engineering. This is made plain in the report on the work of the laboratory for 1965 (H.M.S.O., 6s. 6d.). The steering committee says that its review of the work of the laboratory, undertaken on its transfer to the Ministry of Technology from the old Department of Scientific and Industrial Research at the beginning of April 1965, had convinced it that chemical engineering and mineral science and technology are "entirely appropriate" in the continuing programme, but that there are advantages in combining these separate divisions into one establishment. In addition the laboratory will continue its work on air pollution, although this is recognized to be somewhat separate from the principal purposes of the Ministry. When it was first established, the laboratory was intended to pursue a flexible programme of research and, for this reason, a substantial programme on ergonomics is being continued. The laboratory has, for example, developed a dentist's chair based on ergonomic principles; the intention is somehow to ease the strain of maintaining "undesirable working postures" chiefly by means of hydraulic- 